\title{
Algunas consideraciones a propósito del ámbito subjetivo de la nueva Ley de Contratos del Sector Público de 2017. En particular, el caso de las Corporaciones de Derecho público
}

\author{
Mariano López Benítez \\ Universidad de Córdoba \\ mariano.lopez@uco.es
}

\begin{abstract}
NOTA BIOGRÁFICA
Doctor en Derecho por la Universidad de Córdoba; Catedrático de Derecho Administrativo en la Universidad de Córdoba. Sus líneas fundamentales de investigación son la Administración y Derechos Fundamentales, la Organización administrativa, el Derecho urbanístico y el Derecho Administrativo económico.
\end{abstract}

\section{SUMARIO}

I. Denominación y ámbito subjetivo de la Ley. II. El esquema general del ámbito subjetivo de aplicación de la Ley: la sujeción de los Poderes Públicos que no son Administración. III. Dos elementos novedosos. IV. El sometimiento a la Ley de partidos políticos y organizaciones sindicales y empresariales. V. Las Corporaciones de Derecho Público.

\section{DENOMINACIÓN Y ÁMBITO SUBJETIVO DE LA LEY}

Aparentemente, el art. 3 de la nueva Ley 9/2017, de 8 de noviembre, de Contratos del Sector Público, por la que se transponen al ordenamiento jurídico español las Directivas del Parlamento Europeo y del Consejo 2014/23/UE y 2014/24/UE, de 26 de febrero de 2014 reproduce el esquema que nos han hecho familiar los anteriores textos legislativos en materia de contratación pública. Al igual que la LCSP de 2007 y el TRLCSP de 2011, la nueva LCSP sigue jugando con el triángulo Sector Público-Poder AdjudicadorAdministración Pública conforme al cual cada uno de sus vértices describe también una distinta forma de sujetarse a los mandatos y contenidos de la LCSP. Sin embargo, tal semejanza resulta sólo aparente, puesto que, como advertiremos en esta breve nota, existen algunos cambios realmente significativos.

Como premisa tal vez convenga destacar que no hay una correspondencia fiel entre la denominación de la Ley -Ley de Contratos del Sector Público- y su ámbito subjetivo de aplicación en la medida en que no sólo se incluyen dentro del sector público entidades privadas -como las Mutuas colaboradoras con la Seguridad Social-, sino que, al mismo tiempo, se acoge también una noción amplia del Sector Público, coincidente -desde luego- con la que se baraja en el ámbito del Derecho Presupuestario, pero no con la concepción más restringida de sector público que tienen, por ejemplo, las Leyes 39 y 40 de 2015, de Procedimiento Administrativo Común y de Régimen Jurídico del Sector Público, respectivamente. Es decir, pese a los píos deseos unificadores que el ya lejano Informe CORA sentaba al respecto, lo cierto es que seguimos donde estábamos, esto es, en que cada norma administrativa recurre al concepto de sector público que más conviene a sus propios objetivos: así no se baraja el mismo concepto de sector público cuando se tratan de determinar los salarios o de regular la tasa de reposición de personal al servicio de las entidades e instituciones públicas, que cuando, por el contrario, se pretende establecer el régimen jurídico de este mismo personal, la normativa de reutilización de la información pública, la regulación de los patrimonios públicos o cuando, en fin, se quieren regular los contratos que aquellas Entidades e Instituciones realizan. 
De todos modos, la inadecuación entre la denominación de la LCSP y su ámbito de aplicación no acaba en los extremos señalados: primero, porque en línea con las anteriores normas de contratos y, por supuesto, con las Directivas de las que aquéllas y esta Ley traen causa, al hilo de los contratos subvencionados (art. 23) continúa existiendo la sujeción a la Ley de contratos que celebren los particulares si tales contratos resultan financiados de forma directa y en más de un $50 \%$ de su importe por entidades que tengan la consideración de poderes adjudicadores.

En segundo lugar, también pueden quedar sujetos a la Ley -no se sabe bien por cierto en qué condición- los partidos políticos, las organizaciones sindicales y empresariales, las fundaciones y asociaciones vinculadas a las anteriores entidades (art. 3.4) y las Corporaciones de Derecho Público (art. 3.5).

Ciertamente, así las cosas, tal vez hubiese resultado más apropiado llamar a la Ley de otra forma. Más aún, cuando se observa que en muchos de estos casos el nexo que lleva a alargar el ámbito subjetivo de aplicación de la LCSP no es otro que la instrumentación de los contratos a través del manejo de fondos públicos.

\section{EL ESQUEMA GENERAL DEL ÁMBITO SUBJETIVO DE APLICACIÓN DE LA LEY: LA SUJECIÓN DE LOS PODERES PÚBLICOS QUE NO SON ADMINISTRACIÓN}

La apariencia de continuidad entre el ámbito subjetivo de aplicación de la nueva LCSP y el de las anteriores leyes de contratación del sector público, se percibe igualmente en la importancia que, pese a estar estableciendo un código de la contratación pública, se le sigue confiriendo a las Administraciones Públicas y a los contratos de las Administraciones Públicas, los cuales continúan representando -en palabras de la Exposición de Motivos- «la parte troncal de esta Ley y la referencia de cualquier contrato que se haga por una entidad del sector público». De este modo, en lo que respecta al grado de sujeción a las determinaciones de la Ley, la LCSP mantiene esa metodología -que ya se ha ido haciendo clásica-conforme a la cual y como si de la realización de una operación aritmética de resta se tratase, se parte de un minuendo de sujeción plena a la Ley para las entidades que tienen la consideración de Administraciones Públicas para ir introduciendo, a partir de él, sucesivos sustraendos que van relajando la intensidad aplicativa de la LCSP para las Entidades que son simples Poderes Adjudicadores y para las restantes Entidades del Sector Público que ni tan siquiera gozan de esa condición de Poder Adjudicador.

En este sentido, resulta reseñable que el art. 3.2 a) LCSP haya devuelto a las Universidades Públicas la condición de Administraciones Públicas que tanto la LPAC como la LRJSP parecen negarles -al menos, formalmente-. Sin embargo, amén de saludar el retorno a la casa del padre de estas entidades, bueno será insistir en la incongruencia que representa que las Universidades Públicas no ostenten la misma condición para estas tres Leyes administrativas, tradicionalmente tan importantes de cara a la caracterización y vertebración de la Administración Pública y del Derecho Administrativo. Por otro lado, conviene traer a colación que la sujeción de las Universidades Públicas a la LCSP es plena y se produce con la misma rotundidad que para las restantes Administraciones Públicas, ya que las especialidades contemplada para ellas en materia de clasificación por la Disposición Adicional sexta de la LCSP se refieren únicamente a su faceta de contratista y no a la de Administración contratante.

Tanto confía el legislador en la bondad de la metodología seguida que le cuesta mucho apartarse de ella. En la redacción originaria del Proyecto de Ley que entró para su tramitación en las Cortes Generales, el art. 3 LCSP, llevado de esta fidelidad ciega a su sistemática y en concordancia con lo que, hasta su derogación por la Ley 25/2013, de 27 de diciembre, establecía el art. 3.2 f) TRLCSP, atribuía la condición de Administraciones Públicas a Poderes e Instituciones Públicas que no son Administración, extensión que, de haberse mantenido en el texto final de la LCSP, persistiría en la confusión creada inicialmente por el TRLCSP acerca del campo de aplicación del Derecho Administrativo, y acerca también de la propia noción de Administración Pública. Pese a ello, pienso que de la interpretación que cabía hacer del propio art. 3.2 del Proyecto de Ley -como de la que era factible hacer en torno al originario art. 3.2 f) TRLCSP- se disipaban tales riesgos, puesto que, en mi opinión, los textos citados dejaban bien claro que la consideración de Administraciones Públicas que se otorgaba a «los órganos competentes del Congreso de los Diputados, del Senado, del Consejo General del Poder Judicial, del Tribunal Constitucional, del Tribunal de Cuentas, del Defensor del Pueblo, de las Asambleas Legislativas de las Comunidades Autónomas y de las instituciones autonómicas análogas al Tribunal de Cuentas y al Defensor del Pueblo» [art. 3.1 I)] era «a los efectos de esta Ley» y «en lo que respecta a su actividad contratación». Es decir, a la postre, la LCSP se alineaba en este punto con esa utilización meramente 
táctica e instrumental del Derecho Administrativo y de la jurisdicción contencioso-administrativa propiciadas por el art. 1.3. a), b) y c) LJCA. Lo que sucede es que, a diferencia de cómo lo hace la LJCA [«Los Juzgados y Tribunales del orden contencioso-administrativo (...) conocerán también de las pretensiones que se deduzcan en relación con los actos y disposiciones en materia de personal, administración y gestión patrimonial» de esas Instituciones y Poderes Públicos], la LCSP se convertía en prisionera de su propia metodología y sistemática y trataba de cerrar su propia construcción. Nada de ilógico ni de reprochable hay en que los contratos de obra, de servicios o de suministro que concluyan, por ejemplo, el Congreso de los Diputados o el Senado se sujeten a las mismas reglas y con idéntica intensidad que los contratos que, con iguales objetos, realicen las Administraciones Públicas, ya que, en definitiva, en uno y otro caso se trata de contratos cuya financiación procede del mismo erario público, y que satisfacen semejantes necesidades instrumentales de las instituciones y de las Administraciones Públicas respectivas. Ahora bien, para alcanzar tal empresa hubiera bastado con reproducir la técnica normativa de la LJCA; una técnica mediante la cual se consiguen los logros apetecidos sin tener que recurrir a giros que aparentemente podrían entrañar una indebida adulteración de los conceptos de Administración Pública y de Derecho Administrativo.

Sin embargo, el problema nacía precisamente de lo que he señalado: de que la LCSP se acoge a una sistemática muy cerrada, en la que la escala de sujeción a los contenidos y mandatos de la Ley viene determinada por el vértice que cada entidad ocupe en ese triángulo Administración Pública-Poder AdjudicadorEntidad del Sector Público. Como el mayor y más pleno grado de sometimiento a las determinaciones de la LCSP se produce en relación con los contratos que concluyan las Administraciones Públicas, el legislador tendría que optar a la hora de determinar el régimen jurídico de los contratos de estas Instituciones y Poderes Públicos que no son Administración por una de estas dos posibilidades: o bien romper con esa sistemática aparentemente omnicomprensiva que él mismo ha creado, o bien mantenerse fiel a ella, aunque para ello tenga que recurrir a la ficción legal de investir como Administraciones Públicas a entidades que no lo son, con la sola finalidad de que su actividad de contratación se sujete con la misma intensidad a los dictados de la LCSP que la de los contratos realizados por las Administraciones Pública en sentido estricto.

Afortunadamente, durante la tramitación parlamentaria se ha arreglado tal entuerto; se ha modificado la redacción del art. 3.2 I) para sacar del mismo a esas Instituciones y Poderes Públicos que no son Administraciones Públicas y se ha mantenido, no obstante, lo que se quería decir -la sujeción plena a la LCSP de los contratos que realicen estos Poderes e Instituciones-, aunque diciéndolo de una manera mucho más elegante y precisa, que no fuerza las categorías ni las nociones básicas del Derecho Administrativo. La Disposición Adicional 46. ${ }^{a}$ de la LCSP preceptúa ahora que:

«Los órganos competentes del Congreso de los Diputados, del Senado, del Consejo General del Poder Judicial, del Tribunal Constitucional, del Tribunal de Cuentas, del Defensor del Pueblo, de las Asambleas Legislativas de las Comunidades Autónomas y de las instituciones análogas al Tribunal de Cuentas y al Defensor del Pueblo ajustarán su contratación a las normas establecidas en esta Ley para las Administraciones Públicas.».

\section{DOS ELEMENTOS NOVEDOSOS CON RESPECTO AL ÁMBITO SUBJETIVO DE APLICACIÓN}

Decía hace un momento que la LCSP construye una metodología propia a la hora de trazar su ámbito subjetivo de aplicación y que trata de mantenerse fiel a la misma. Sin embargo, interesa poner de relieve que, cuando quiere, rompe, sin embargo, con esa sistemática y adopta una perspectiva absolutamente distinta. Así sucede en lo respecta a la sujeción a la LCSP tanto de los partidos políticos, organizaciones sindicales y empresariales y fundaciones y asociaciones vinculadas con cualquiera de ellas, como de las Corporaciones de Derecho Público.

\section{EL SOMETIMIENTO A LA LEY DE LOS PARTIDOS POLÍTICOS Y ORGANIZACIONES SINDICALES Y EMPRESARIALES}

Como una de sus grandes novedades en lo atañedero a su ámbito subjetivo de aplicación, la Exposición de Motivos de la LCSP proclama que «se ha extendido» dicho ámbito «con la idea de aplicar estas normas a entidades no sujetas». Así -continúa diciendo la Exposición de Motivos-, «se han incluido los partidos políti- 
cos, las organizaciones sindicales y las empresariales, así como las fundaciones y asociaciones vinculadas a cualquiera de ellos siempre que se cumplan determinadas circunstancias como que su financiación sea mayoritariamente pública y respecto de los contratos sometidos a regulación armonizada».

Originariamente, el art. 3.4 del Proyecto de Ley aplicaba a estas entidades -al menos, para los contratos sujetos a regulación armonizada que llevasen a cabo- el estatus de Poder Adjudicador siempre que para ello cumplieran alguna de las condiciones fijadas por el Derecho y la Jurisprudencia europeos y recordadas también por el art. 3.3 d) tanto del Proyecto de Ley como de la LCSP en su redacción final: esto es, además de que posean personalidad jurídica y desempeñen una actividad de interés general que no revista carácter industrial o mercantil, alternativamente se requiere que uno o varios poderes adjudicadores financien mayoritariamente su actividad; que controlen su gestión; o que nombren a más de la mitad de los miembros de su órgano de administración, dirección o vigilancia. Evidentemente de estas tres condiciones últimas sólo resultaría factible aplicarles a las mencionadas entidades la relativa a la financiación, razón por la que la Exposición de Motivos sólo aludía y alude a ella. Aplicación, sin embargo, no exenta de dificultades, habida cuenta de que todas estas entidades de las que se habla, junto a los recursos provenientes de la financiación pública, disfrutan asimismo de recursos privados (cuotas y aportaciones de sus afiliados; productos de las actividades propias y de los servicios prestados por la organización; rendimientos de su patrimonio; herencias, donaciones, fondos procedentes de préstamos etc.), como advierte, por ejemplo, el art. 2 de la Ley Orgánica 8/2007, de 4 de julio, de Financiación de los Partidos Políticos. En consecuencia, determinar si concurre o no la condición de que se financien mayoritariamente a través de recursos públicos entraña una cuestión de carácter cuantitativo que, al menos, para los partidos, sindicatos y organizaciones empresariales no parece de difícil dilucidación, de ahí que la Exposición de Motivos casi prejuzgue su existencia.

Pero, volviendo a esa redacción originaria del art. 3.4 del Proyecto de Ley, lo que conviene recordar es que, concurriendo esas circunstancias, a los contratos que realizasen les resultaba de aplicación, según aquella primitiva redacción, «la regulación establecida en el Título I del Libro Tercero de la presente Ley». De esta forma, a los contratos sujetos a regulación armonizada que concertasen estas organizaciones se les aplicaban, de acuerdo con lo previsto por el art. 316 del Proyecto, las Secciones $1 .^{a}$ y $2 .^{a}$ del capítulo I del Título I del Libro II de la Ley (arts. 115-185), en lo referente a la preparación y adjudicación de los contratos. Además, por expresa determinación del mencionado art. 316 se les aplicaban también los preceptos relativos a las obligaciones en materia medioambiental, social o laboral (art. 199); a las condiciones especiales de ejecución (art. 200); a los supuestos de modificación del contrato (arts. 201-203); a las determinaciones en materia de cesión y subcontratación (arts. 212 a 215); a la racionalización técnica de la contratación (arts. 216 a 226); y, en fin, la consideración de la imposibilidad de ejecutar la prestación en los términos inicialmente pactados cuando no sea posible modificar el contrato conforme a los arts. 202 y 203 como causa de resolución de los contratos.

Frente a esta exigente y ejemplar aplicación extensiva de la Ley a quienes, en puridad, no son Poderes Adjudicadores, la tramitación parlamentaria ha dado fruto a una regulación muy diferente. Dice ahora el art. 3.4 lo siguiente:

«Los partidos políticos, en el sentido definido en el artículo 1 de la Ley Orgánica 8/2007, de Financiación de los Partidos Políticos; así como las organizaciones sindicales reguladas en la Ley Orgánica 11/1985 de 2 de agosto, de Libertad Sindical, y las organizaciones empresariales y asociaciones profesionales a las que se refiere la Ley 19/1977, de 1 de abril, sobre regulación del derecho de asociación sindical, además de las fundaciones y asociaciones vinculadas a cualquiera de ellos, cuando cumplan los requisitos para ser poder adjudicador de acuerdo con la letra d) del apartado 3 del presente artículo, y respecto de los contratos sujetos a regulación armonizada deberán actuar conforme a los principios de publicidad, concurrencia, transparencia, igualdad y no discriminación sin perjuicio del respeto a la autonomía de la voluntad y de la confidencialidad cuando sea procedente.

Los sujetos obligados deberán aprobar unas instrucciones internas en materia de contratación que se adecuarán a lo previsto en el párrafo anterior y a la normativa comunitaria, y que deberán ser informadas antes de su aprobación por el órgano al que corresponda su asesoramiento jurídico. Estas instrucciones deberán publicarse en sus respectivas páginas web.».

Es decir, el régimen jurídico que ahora se aplica a sus contratos sujetos a regulación armonizada concertados por los partidos políticos, organizaciones sindicales y empresariales y fundaciones y asociaciones vinculadas con cualquiera de estas entidades no es ya el que se aplica a este tipo de contratos cuando lo 
realizan Poderes Adjudicadores en sentido estricto que no tengan la condición de Administraciones Públicas -como sucedía en la redacción originaria-, sino un régimen jurídico incluso más liviano que el que art. 319 LCSP traza para los contratos que realicen las Entidades del Sector Público que no tengan el carácter de poderes adjudicadores. Lo que, a mi juicio, significa que, pese a que el introito del art. 3.4 LCSP no ha cambiado y se mantiene idéntico a como lo estaba en el Proyecto de Ley originario, las modificaciones introducidas en su parte final han terminado por arrumbar la ficción legal de considerar poderes adjudicadores a estas organizaciones al menos para el reducido ámbito de los contratos sujetos a regulación armonizada que concluyan.

No parece que los tiempos que corren y las difíciles condiciones sociales y económicas en las que nos movemos, unido al progresivo desapego que la ciudadanía viene mostrando hacia estas organizaciones, constituyan las circunstancias más propicias para haber realizado tales cambios; cambios que se suman a la exclusión prevista con respecto a los contratos que tengan por objeto servicios relacionados con campañas políticas, incluidos en los códigos CPV 79341400-0, 92111230-3 y 92111240-6 cuando sean adjudicados por un partido político (art. 11.5 LCSP).

\section{LAS CORPORACIONES DE DERECHO PÚBLICO}

La perplejidad en lo que respecta a la regulación del ámbito subjetivo de aplicación de la LCSP gana enteros cuando se repara en su art. 3.5, dedicado a las Corporaciones de Derecho Público:

«Asimismo, quedarán sujetos a esta Ley las Corporaciones de derecho público cuando cumplan los requisitos para ser poder adjudicador de acuerdo con el apartado tercero, letra d) del presente artículo.».

Antes de abordar la exégesis del precepto transcrito, no parece que haya que poner reparos a que, bajo determinadas circunstancias, algunos de los contratos que realicen las Corporaciones de Derecho Público deban quedar -con mayor o menor intensidad- sujetos a la normativa de contratos públicos. Así sucede, desde luego, con los contratos que realicen y que estén subvencionados de forma directa y en más de un $50 \%$ por poderes adjudicadores.

Mas, sentada la premisa anterior, lo que hay que tratar de dilucidar es qué ha querido decir exactamente el art. 3.5, puesto que las interrogantes que al respecto se abren son numerosas: ¿se consideran Administraciones Públicas a las Corporaciones de Derecho Público y, por ello, quedan sujetas como tales a la LCSP? ¿se establece, en cambio, la ficción legal de que son Poderes Adjudicadores y se les aplica consiguientemente el régimen contractual previsto por la LCSP para los Poderes Adjudicadores que no tengan la consideración de Administraciones Públicas? ¿Es la invocación del art. 3.3 d) una simple remisión para determinar cuándo se les va a aplicar la LCSP, pero sin comunicarles por ello -ni tan siquiera a título de ficción legal- la condición de Poder Adjudicador? ¿Es factible que las Corporaciones de Derecho Público -o, al menos, todas ellas- cumplan con alguno de esos requisitos de los que habla el art. $3.3 \mathrm{~d}$ )?

Como se ve, son muchas las preguntas que se plantean en relación con este intrincado precepto, cuestiones cuya interpretación no resulta, desde luego, fácil. Si recurriéramos de nuevo a esa metodología en la que, como un deus ex machina, se recrea la LCSP a la hora de trazar su ámbito subjetivo de aplicación, podría traerse aquí a colación una primera respuesta que dejaría sin sentido todas las demás cuestiones que nos hemos planteado anteriormente. Es sabido que para un sector doctrinal -es verdad que minoritario- las Corporaciones de Derecho Público son Administraciones Públicas en sentido estricto, conformando lo que esa doctrina califica como Administración Corporativa. Pues bien, podría pensar que el legislador se ha fajado en la disputa doctrinal acerca de la naturaleza jurídica de las Corporaciones de Derecho Público y ha tomado partido, declarando la condición de Administraciones Públicas de éstas. Si así fuera, el círculo, como decíamos, habría quedado cerrado: como Administraciones Públicas estarían sujetas a la LCSP en el mismo grado y con idéntica intensidad en que lo están las demás Administraciones Públicas a las que alude la LCSP. Los problemas hermenéuticos habrían acabado.

Sin embargo, la aceptación de esta interpretación tropieza con importantes obstáculos en la propia LCSP. Si el legislador hubiese creído que son Administraciones Públicas, lo lógico es que entre ellas hubiera mencionado también a las Corporaciones de Derecho Público, cosa que el art. 3.2 LCSP no hace, ni siquiera en la manera en que lo hacía, como hemos visto, el Proyecto de Ley con respecto a los Poderes Públicos. Es más, si así fuese, hubiera sido necesario que las Corporaciones de Derecho Público aparecieran integradas 
en el rol de entidades que conforman el sector público. Cosa que tampoco ocurre, salvo que las entendiéramos comprendidas en ese cajón de sastre con el que concluye el art. $3.1 \mathrm{~g}$ ) («cualesquiera entidades de derecho público con personalidad jurídica propia vinculadas a un sujeto que pertenezca al sector público o dependientes del mismo»); inclusión que tampoco resultaría acertada porque ese precepto se está refiriendo al sector público institucional y no a las Corporaciones que describen un fenómeno organizativo muy diferente. Además, aun admitiendo a título de hipótesis la procedencia de tal inclusión, carecería de sentido que después se dedicase un precepto específico a las Corporaciones de Derecho Público. Constituiría una redundancia innecesaria de difícil explicación.

Por tanto, no parece que la intención de la LCSP haya sido la de considerar las Corporaciones de Derecho Público como Administraciones Públicas. Siendo ello así, lo procedente es seguir profundizando en la interpretación del precepto. En este sentido, es oportuno recordar que el art. 3.5 dice que las Corporaciones de Derecho Público quedan sujetas a la LCSP «cuando cumplan los requisitos para poder ser adjudicador de acuerdo con el apartado tercero, letra d) del presente artículo». ¿Se ajustan las Corporaciones de Derecho Público a alguno de esos requisitos? Si los cumplen, ¿se convierten en Poder Adjudicador y quedan sometidos al régimen jurídico contractual propio de los Poderes Adjudicadores?

Como ya ha recordado abundantemente la jurisprudencia europea [por todas, la reciente STJUE de 5 de octubre de 2017, LitSpecMet y Vilniaus, as. C-567/15, ECLI:EU:C:2017:736] una entidad adquiere la condición de Poder Adjudicador cuando se cumplen tres condiciones acumulativas, a saber, a) que dicha entidad haya sido creada específicamente para satisfacer necesidades de interés general que no tengan carácter industrial o mercantil; b) que esté dotada de personalidad jurídica; y c) que su actividad esté mayoritariamente financiada por los poderes públicos o que su gestión esté controlada por parte de éstos últimos, o que más de la mitad de los miembros de su órgano de administración, de dirección o de vigilancia sean nombrados por los poderes públicos. Estas tres condiciones son acumulativas, siendo, en cambio, alternativos los requisitos a los que se refiere la condición expresada en la letra c). Y, precisamente, la concurrencia o no de uno de estos tres requisitos de la letra c) es lo que va a determinar si las Corporaciones de Derecho Público de base sectorial cumplen con las condiciones para ser poder adjudicador o no, ya que es notorio tanto que cuentan con una personificación jurídica de derecho público como que el grueso de las actividades que realizan se destinan a satisfacer necesidades que no tienen carácter industrial o mercantil.

En esencia, las Corporaciones de Derecho Público representan, como se sabe, un fenómeno de autoadministración mediante el cual quienes participan del ejercicio de una misma profesión titulada, o comparten un mismo arte u oficio de carácter económico se autorregulan para representar y defender sus intereses corporativos y desempeñar asimismo todas aquellas funciones públicas que la Administración Pública pueda atribuirles o delegarles. Por tanto, una nota fundamentalísima de su régimen jurídico es que las personas que conforman el sustrato social de la Corporación son quienes nombran e integran sus órganos de gobierno a través de los cuales se delinean los actos de voluntad de la Corporación, comenzando por sus propios Estatutos y reglas de funcionamiento. Por consiguiente, no resulta factible que, con respecto a las Corporaciones de Derecho Público, pueda cumplirse el requisito de que los Poderes Adjudicadores «nombren a más de la mitad de los miembros de su órgano de administración, dirección o vigilancia», puesto que -si así fuese- se habría desnaturalizado el concepto mismo de Corporación al faltar, como decimos, uno de sus caracteres más esenciales.

Tampoco parece asumible - 0 , al menos, no asumible con carácter general para toda la tipología existente de Corporaciones de Derecho Público- el requisito de que su financiación corra mayoritariamente a cargo de los Poderes Adjudicadores. Desde luego, no sucede así con los dos tipos más importantes de Corporaciones de Derecho Público existentes en nuestro ordenamiento jurídico: los Colegios Profesionales y las Cámaras de Comercio, Industria, Servicios y Navegación.

Los Colegios Profesionales se financian mayoritariamente con las cuotas o derramas que abonan sus colegiados y con los productos y rentas que obtienen de las actividades y servicios que organizan a favor de sus miembros y de la sociedad. Es verdad que las Administraciones Públicas suelen subvencionarles o retribuirles las funciones públicas que, por atribución legal o delegación, les prestan. Sin embargo, tales transferencias no sólo no suponen el montante de ingresos más relevante de sus presupuestos, sino que, en numerosas ocasiones, los Colegios actúan como simples canalizadores de los pagos debidos a sus colegiados. El ejemplo de la prestación del servicio público de asistencia jurídica gratuita que la Ley 1/1996, de 10 de enero, instrumenta a través de los Colegios de Abogados y de Procuradores resulta muy significativo al respecto. Los Colegios examinan la viabilidad de las pretensiones de los solicitantes de justicia gratuita, 
les asignan Letrado o Procurador de oficio y vigilan el correcto cumplimiento por éstos de los deberes profesionales; sin embargo, apenas si retienen una cantidad mínima, en concepto de gastos de funcionamiento, de las cantidades que la Administración abona por la prestación del referido servicio público, cantidades que mayoritariamente van destinadas directamente a remunerar los servicios profesionales correspondientes al turno de oficio prestados individualmente por los colegiados.

Lo mismo puede afirmarse con respecto a las Cámaras de Comercio, Industria, Servicios y Navegación. La supresión del recurso cameral obligatorio -al que se le atribuía naturaleza tributaria- y su sustitución por las cuotas, derramas o aportaciones voluntarias que realicen sus miembros, hace que, con ello, se diluya también la posibilidad de que estos entes corporativos resulten financiados mayoritariamente por uno o varios Poderes Adjudicadores, más allá de lo que signifiquen las transferencias que las Administraciones puedan hacerles como remuneración de las funciones públicas que, en su caso, les atribuyan y que difícilmente ostentarán ese carácter de financiación mayoritaria exigido por la norma.

Hemos chequeado brevemente la viabilidad del requisito de la financiación con respecto a estos dos tipos de Corporaciones de Derecho Público de carácter sectorial, pero pensamos que las conclusiones alcanzadas resultan asimismo aplicables a la gran mayoría de las restantes Corporaciones de Derecho Público de esta clase. Las fronteras más difíciles con las que podríamos encontrarnos se situarían tal vez en relación con aquellos entes corporativos -como las Cámaras Agrarias- en los que la pérdida de ingresos por la supresión de las cuotas obligatorias se ha tratado de enjugar mediante subvenciones directas de la Administración. Sin embargo, también hay que reconocer que, con la derogación de la normativa básica estatal en materia de Cámaras Agrarias, la práctica totalidad de éstas han desaparecido, siendo sus activos patrimoniales traspasados a las organizaciones profesionales agrarias y sus relaciones jurídicas y obligacionales asumidos por la Administración. En otros casos, como acontece con respecto a las Cofradías de Pescadores, las Leyes autonómicas han tratado de potenciar y poner en relieve tanto la actividad comercializadora como la gestión de espacios portuarios que, desde antiguo, han venido constituyendo una parte muy significativa del presupuesto de ingresos de estas entidades.

En fin, el análisis en torno al cumplimiento del tercer requisito enunciado por el art. 3.3 d) LCSP quizá sea el que revista mayor complejidad, ya que su concurrencia o no dependerá del significado e importancia que se le otorgue al control que las Administraciones Públicas realizan con respecto a las Corporaciones de Derecho Público de base sectorial. No se oculta que las Corporaciones de Derecho Público están sujetas a controles por parte de la Administración. Con razón se ha señalado que los controles administrativos existentes sobre las Corporaciones de Derecho Público, por las características que representan, sean en nuestros días el último reducto que le quede a la «tutela» administrativa. Una tutela que, conforme a su caracterización clásica, se restringe sólo a las potestades administrativas de control que vengan atribuidas expresamente y con carácter tasado por la Ley; pero que abarcan aspectos muy diversos y significativos de la vida de la Corporación, y no ceñidos exclusivamente al control del ejercicio de las funciones públicas que les han sido confiadas. En función de la tipología de Corporación en la que nos movamos, el ámbito de la tutela administrativa ejercida sobre ellas variará. Así, puede hablarse de la existencia de potestades de control sobre los órganos corporativos (que van desde su convocatoria hasta la suspensión o disolución de los mismos ante supuestos de grave incumplimiento de sus obligaciones); de potestades de control sobre sus actos y disposiciones (requiriéndose de aprobaciones y autorizaciones administrativas para algunos de ellos, como para la aprobación de sus Reglamentos de Régimen Interior); e, incluso de la sujeción a autorizaciones o a comunicaciones previas de los actos de disposición que la Corporación pretenda emprender sobre sus bienes. Dando un paso más, la Ley 20/2015, de 14 de julio, permite -al menos, para las Cámaras de Comercio que están sujetas a la tutela de la Administración General del Estado- diseñarles un Plan de Viabilidad económica, cuyo incumplimiento puede desembocar en la disolución de la Cámara de que se trate. En todo caso, conviene destacar que, salvo supuestos muy dramáticos en los que la preservación de la pervivencia del ente corporativo requiere el recurso a supuestos de sustitución, intervención o disolución de sus órganos, lo normal es que los controles que ejerce la Administración de tutela sobre la actividad de los órganos corporativos se constriñan a la realización de simples controles de legalidad realizados a posteriori sobre determinados actos y disposiciones de gran importancia.

En este sentido, la Sentencia del Tribunal de Justicia de la Unión Europea de 12 de septiembre de 2013, caso IVD Ärztkammer Westfalen-Lippen, as. C-526/11, ECLI:EU:C:2013:543, respecto a un caso en el que lo que se debatía era si la licitación de la impresión y distribución del boletín informativo del Colegio de Médicos (Ärztekammer) de Westfalen-Lippe había de sujetarse a las normas de contratación, considera que en lo relativo 
«al control de la gestión por parte de los poderes públicos, procede recordar que, en principio, un control a posteriori no cumple dicho criterio cuando tal control no permite a los poderes públicos influir en las decisiones del organismo de que se trata en materia de contratos públicos (...). Por tanto, -concluye el Tribunal-, tal es el caso, en principio de un control general de legalidad realizado a posteriori por una autoridad de supervisión y, con mayor motivo, de una intervención por parte de dicha autoridad en forma de aprobación de la resolución del mencionado organismo por la que se fija el importe de las cuotas que garanticen la parte esencial de su financiación, que se limite a verificar que el presupuesto del citado organismo sea equilibrado.» (ap. $\left.29 .{ }^{\circ}\right)$.

La decisión parcialmente transcrita invoca además en su apoyo la importante STJCE de 27 de febrero de 2003, Adolf Truley, as. C-373-00, ECLI:EU:C:2003:110, la cual sentó los caracteres generales de este requisito del control de la gestión en los siguientes términos:

«... en cuanto al criterio relativo al control de la gestión, el Tribunal de Justicia ha declarado que dicho control debe originar una dependencia del organismo de que se trate frente a los poderes públicos, equivalente a la que existe cuando se cumple uno de los otros dos criterios alternativos, a saber que la financiación proceda mayoritariamente de los poderes públicos o que éstos nombren a la mayoría de los miembros del órgano de administración, de dirección o de vigilancia de ese organismo, permitiendo así a los poderes públicos influir en las decisiones de dicho organismo en materia de contratos públicos.

En virtud de esta jurisprudencia, queda descartada la posibilidad de considerar que se cumple el requisito de control de la gestión en el supuesto de un mero control a posteriori ya que, por definición, tal control no permite que los poderes públicos influyan en las decisiones del organismo de que se trate en materia de contratos públicos.» (aps. 68. ${ }^{\circ}$ y $69 .{ }^{\circ}$ ).

Por tanto, conforme a esta jurisprudencia, no parece que, al menos en lo concerniente a los Colegios Profesionales y a las Cámaras de Comercio, resulte viable entender que las respectivas Administraciones de tutela, a través del control a posteriori que ejercen en relación con algunos de los actos corporativos, lleguen a tener esa influencia determinante sobre las decisiones del organismo requeridas por la jurisprudencia comentada.

La cuestión puede resultar, en cambio, más comprometida con respecto a otras Corporaciones de Derecho Público -pensamos en estos momentos en las Juntas de Compensación urbanísticas- cuya vinculación con la Administración de tutela parece ser más estrecha que la existente en relación con las Cámaras y los Colegios hasta el punto de que la Administración se reserva, con carácter general, la potestad de revocar en alzada los acuerdos adoptados; aprueba sus Estatutos y Bases de Actuación, así como los Proyectos que en su seno se adopten; las cuotas de urbanización que abonan sus miembros -que poseen naturaleza de prestación patrimonial de carácter público- constituyen su principal fuente de financiación y para su recaudación gozan de la vía de apremio; un representante de la Administración puede integrarse en la Junta etc. Aunque la Junta Consultiva de Contratación (Informe 44/09, de 26 de febrero de 2010) ha negado expresamente que las Juntas de Compensación reúnan la condición de Poder Adjudicador, también es verdad que algunas sentencias del Tribunal de Justicia podrían alimentar dudas al respecto, en la medida en que consideran contratos de obra pública las obras de urbanización que se llevan a cabo en materia urbanística por terceros agentes ajenos a la Administración [STJCE de 21 de febrero de 2008, Comisión contra Italia, as. C-412/04, ECLI:EU:C:2008:102 y STJUE de 26 de mayo de 2011, Comisión contra España, as. C-306-08, ECLI:EU:C:2011:347).

En cualquier caso, las incógnitas vinculadas con la interpretación del art. 3.5 LCSP no concluyen con la constatación de si las Corporaciones de Derecho Público de base sectorial cumplen o no con los requisitos para ser poder adjudicador. El paso siguiente consiste en discernir el grado y forma en que se le aplica la LCSP. El art. 3.5 LCSP resulta poco explícito ya que se limita a indicar que, cuando cumplan los requisitos para ser poder adjudicador, «quedarán sujetos a esta Ley». Desde luego, no parece que lo procedente sea sujetarlas plenamente a la LCSP, dándoseles, por consiguiente, el mismo trato que si fuesen lo que no son, es decir, Administraciones Públicas. Asimismo, entrañaría una complejidad notable sujetarlas plenamente a la LCSP sólo con respecto a los contratos que concertasen relacionados con aquellos supuestos en que ejercen funciones públicas. Esto último no sólo causaría perturbaciones muy graves en el funcionamiento de las propias Corporaciones, sino que las abocaría a arduas disquisiciones en torno a si los contratos de 
obra o de suministro de bienes que concertasen servirían únicamente a esa parte de actividad que desempeñan como vicarios de la Administración o resultarían también útiles a sus fines corporativos. El análisis -cuantitativo y cualitativo- al que obligarían estas posiciones constituiría un nido generador de inseguridad jurídica para las propias Corporaciones. Todo ello sin olvidar además que, aun dentro del tipo de los Colegios Profesionales, se ha producido una inadmisible desnaturalización de la categoría, en la medida en que se ha aplicado legalmente el concepto de Colegio Profesional tanto a asociaciones que integran profesiones no tituladas como a entidades que no desarrollan función pública alguna.

Desechadas, por tanto, ambas interpretaciones, parece que la lógica impondría que su régimen de sujeción a la LCSP fuese el relativo a los Poderes Adjudicadores que no tienen la consideración de Administraciones Públicas, ya que el art. 3.5 LCSP declara expresamente que se sujetan a la Ley «cuando cumplan los requisitos para ser poder adjudicador». Conclusión que, aparte de los problemas y dudas interpretativos ya reseñados anteriormente en relación con los partidos políticos, supone también que la LCSP rompe doblemente con su propia sistemática: por un lado, atribuye la condición de Poder Adjudicador a entes a los que, como hemos visto, les resulta muy forzada tal atribución. Por otro lado, en ese camino del menos al más -de entes integrantes del sector público a Administraciones Públicas- en el sometimiento a la Ley que el art. 3 LCSP traza, nos hallaríamos ante unos entes -las Corporaciones de Derecho Público- a los que se atribuye la condición de Poder Adjudicador sin formar parte al mismo tiempo del sector público. Porque conviene recordar que ninguna Ley administrativa considera las Corporaciones de Derecho Público de base sectorial, no ya como Administraciones Públicas, sino ni tan siquiera como entidades integrantes del Sector Público. A lo más, el art. 2.4 LPAC preceptúa que «las Corporaciones de Derecho Público se regirán por su normativa específica en el ejercicio de las funciones públicas que les hayan sido atribuidas por Ley o delegadas por una Administración Pública», normativa específica que, aunque en la práctica por el juego de los reenvíos normativos termine siendo la LPAC, no se dice expresamente que sea ésta, cuyo valor -conforme a lo que dictamina el propio art. 2.4 LPAC- es meramente supletorio. Completando esta idea el art. $2 \mathrm{c}$ ) LJCA sujeta al conocimiento de la jurisdicción contencioso-administrativa «los actos y disposiciones de las Corporaciones de Derecho Público, adoptados en el ejercicio de funciones públicas». La misma normativa básica de alguna de estas Corporaciones corrobora lo dicho. Por ejemplo, la Ley Básica de Cámaras de Comercio (Ley 4/2014, de 1 de abril) proclama en su art. 2.2 que «la contratación y el régimen patrimonial -de este tipo de entes corporativos- se regirán conforme al derecho privado y habilitando un procedimiento que garantice las condiciones de publicidad, transparencia y no discriminación»; añadiendo su art. 5.6 que las Cámaras de Comercio podrán «celebrar contratos en los que las Administraciones Públicas se acomodarán a las prescripciones» del TRLCSP.

Si lo que está en la base de las Directivas de Contratación es que se sujeten a los procedimientos de las mismas, los contratos que se adjudiquen por organismos públicos o por entidades que se financian mayoritariamente de dinero público, no parece procedente esta asimilación indiscriminada operada en relación con las Corporaciones de Derecho Público, cuya sujeción con carácter general solo estaría justificada plenamente en los casos de los contratos subvencionados que realicen en los términos del art. 23 LCSP. Da la sensación de que la LCSP ha querido operar transponiendo los mismos criterios que la LPAC emplea para cuando las Corporaciones de Derecho Público actúan funciones públicas, supuestos en los que, como hemos visto, la LPAC se remite a una legislación específica que, a la postre, será siempre una legislación específica de naturaleza pública -no privada- con soluciones que, directa o indirectamente, terminarán siendo también idénticas a las contenidas en la propia LPAC. Ahora bien, estas previsiones de la LPAC y de la LJCA, perfectamente lógicas desde el punto de vista del art. 149.1.18 CE que apuesta por garantizar un tratamiento común de los administrados ante el ejercicio de las potestades públicas, no resulta, a nuestro juicio, extrapolable sin más al ámbito de la actividad contractual de las Corporaciones de Derecho Público de base sectorial. Una grandísima parte de la actividad que despliegan muchas de estas Corporaciones no supone ejercicio de funciones públicas, sino actividades de representación, defensa, asistencia y promoción de los intereses corporativos que tienen constitucionalmente encomendados (arts. 36 y $52 \mathrm{CE}$ ). Incluso, con respecto a bastantes de estas Corporaciones de Derecho Público, el ejercicio de funciones públicas ha quedado limitado sólo a ser órganos de consulta de la Administración.

No creemos, por tanto, que el art. 3.5 LCSP marque un sesgo con respecto a la forma en que hasta el momento han venido estando sujetas a la legislación contractual la gran mayoría de las Corporaciones de Derecho Público de base sectorial. Desde luego, no estimamos que los dos tipos más importantes y numerosos de Corporaciones sectoriales existentes en nuestro ordenamiento vayan a verse afectados por este art. 3.5 LCSP, ya que, como hemos expuesto, no parece que sea una interpretación muy acertada entender que 
tanto los Colegios Profesionales como las Cámaras de Comercio cumplen con los requisitos precisos para ser considerados Poder Adjudicador. Afirmación que, sin embargo, no es óbice para que tales entes corporativos, trayendo a primer plano la veste pública que de alguna manera ostentan, sujeten los contratos que realicen a procedimientos que garanticen unas mínimas condiciones de publicidad, transparencia y no discriminación. Que es lo que, en definitiva, vienen proclamando las respectivas normas básicas que los regulan.

De esta suerte, pensamos que el art. 3.5 LCSP presenta, en realidad, un ámbito de aplicación muy reducido y tiene -si se permite la expresión- una marcada naturaleza jurídica de precepto singular en el sentido de que, sin decirlo de manera expresa, trata de sujetar a las prescripciones de la LCAP a las Corporaciones de Derecho Público de base sectorial que operan en los ámbitos de la gestión urbanística, únicos supuestos en los que, recordando la jurisprudencia europea habida al respecto, resultaría factible extender la consideración de Poderes Adjudicadores. A estos casos, cabría sumar también la hipótesis de las Corporaciones de Derecho Público que se dan en el ámbito de la cultura, del conocimiento y de la investigación científica sobre las cuales nuestro Tribunal Supremo, a la vez que ha subrayado que su principal vía de sustentación económica son las asignaciones financieras que reciben de los presupuestos públicos (STS de 23 de julio de 1985), ha destacado también la «tenue, si no directamente inexistente» base privada que ostentan, pues «no hay ningún atisbo de fines privados ni de intereses particulares, a diferencia de lo que es usual en las corporaciones sectoriales de base privada arquetípicas, como pueden ser los colegios profesionales o las cámaras de comercio» (STS de 17 de noviembre de 2015, rec. casación núm. 764/2014, ECLI: ES: TS: 2015: 4791). 